\title{
Differential Activation of Stat3 and Stat5 by Distinct Regions of the Growth Hormone Receptor
}

\author{
Athanassia Sotiropoulos, Soraya Moutoussamy, \\ Françoise Renaudie, Martine Clauss, Christine Kayser, \\ Fabrice Gouilleux, Paul A. Kelly, and Joelle Finidori \\ INSERM Unité 344-Endocrinologie Moléculaire \\ Faculté de Médecine Necker \\ 75730 Paris Cedex 15, France. \\ INSERM Unité 363 - Oncologie Cellulaire et Moléculaire (F.G.) \\ Hôpital Cochin \\ 75730 Paris Cedex 14, France
}

The GH receptor (GHR) is a member of the cytokine receptor superfamily; its signaling involves the activation of Janus tyrosine kinases (JAK2) and Stat (signal transducers and activators of transcription) transcription factors. Using truncated and tyrosine mutants of the receptor, we show that different receptor domains are essential for the activation of Stat3 and Stat5. GH-dependent phosphorylation of JAK2, Stat3, and Stat5, as well as transactivation studies with reporter genes containing Stat 3 and Stat5 DNA-binding elements, was performed in cells expressing the various GHR mutants. The membrane-proximal region of the receptor necessary for JAK2 activation is sufficient for Stat3 activation. In contrast, C-terminal tyrosine residues of GHR are absolutely required for Stat 5 activation. The same residues are also involved in the regulation of JAK2 dephosphorylation, possibly through the activation of a phosphatase. Using in vitro experiments with glutathione-S-transferase-fusion proteins, we demonstrate that the SH2 domain of Stat 5 binds to the carboxy-terminal tyrosine-phosphorylated residues of GHR. Our results show that a cytokine receptor can mediate differently the activation of distinct Stat proteins that could be involved in cytokine-specific effects. (Molecular Endocrinology 10: 998-1009, 1996)

\section{INTRODUCTION}

$\mathrm{GH}$ is a pituitary hormone that promotes growth and exerts a large number of metabolic effects. The GH receptor $(\mathrm{GHR})$ is a single transmembrane protein that belongs to the cytokine receptor superfamily $(1$, 2). These receptors have conserved structural features, including paired cysteine residues and a
WSXWS motif in the extracellular domain; a conserved proline-rich region (box 1 ) is also found in the cytoplasmic domain of most members of the superfamily. While they have no intrinsic enzymatic activity, these receptors associate with and activate members of the Janus kinase (JAK) family (reviewed in Ref. 3). GHR signaling involves ligand-induced homodimerization of the receptor and its association with the tyrosine kinase JAK2 (4); these events initiate a cascade of phosphorylation of cellular proteins, including the kinase itself and the receptor. Stat proteins (signal transducers and activators of transcription) have been shown to participate in cytokine receptor signaling. Six members of the Stat family have been identified to date. Among them, Stat1, Stat3, and Stat5 are involved in many receptor-signaling pathways (reviewed in Ref. 5) including those of GHR (6-8). Genetic and biochemical evidence has demonstrated that Stat proteins are targets of JAK kinases (reviewed in Ref. 9). The mechanism proposed for the activation of these transcription factors involves their tyrosine phosphorylation by the receptor-associated kinases and translocation to the nucleus, where they bind specific DNA sequence motifs, thus contributing to transcriptional activation of cytokine-regulated genes. In addition, it has been reported recently that serine/theonine phosphorylation of some Stat proteins could be important in the regulation of their activity $(10,11)$.

GH regulates the expression of many genes involved in proliferation and differentiation (reviewed in Ref. 12). Among the GH-regulated genes, the serine protease inhibitor, Spi 2.1, has been well characterized (13). The promoter of Spi 2.1 contains a short palindromic sequence that binds Stat5 (8). GH also activates transcription of the c-fos gene (14), and we have shown that GH induces binding of Stat3 to the C-sisinducible element (SIE) of the c-fos promoter (15). We have previously characterized the regions of the re- 
ceptor involved in $\mathrm{GH}$-induced gene transcription. The membrane-proximal domain, containing box 1 , is involved in JAK2 activation but is not sufficient for GHstimulated transcription of Spi 2.1. Additional C-terminal domains of the receptor are important for this effect (16). We have also demonstrated that Stat3 DNA-binding activity induced by $\mathrm{GH}$ does not require the carboxy-terminal region of GHR (15).

In this paper, we focus on regions of the receptor regulating the JAK/Stat pathways to better understand the participation of these proteins in $\mathrm{GH}$-induced transcription. Several truncated and tyrosinesubstituted mutant forms of GHR were constructed. In cells expressing the various GHR mutants, tyrosine phosphorylation kinetics of JAK2 were analyzed, and the activation of Stat3 and Stat5 were measured. For this purpose we developed a functional approach. DNA elements that have been reported to bind Stat proteins and that are present in $\mathrm{GH}$-responsive gene promoters were used to construct reporter genes. Stat3-mediated transcription was measured using the SIE element of the c-fos promoter. Stat5-mediated transcription was evaluated with lactogenic hormone response element (LHRE) and GH response element II (GHREII), which are found in the $\beta$-casein and Spi 2.1 gene promoters, respectively. The use of these regulatory elements, rather than the full-length promoters, allows measurement of transcription mediated primarily by Stat 3 and Stat 5 and evaluation of the contribution of Stat proteins in the regulation of the transcription of the full-length promoter by $\mathrm{GH}$. We identify two carboxy-terminal tyrosine residues important for GHR signaling. These tyrosines probably recruit a tyrosine phosphatase that participates in JAK2 dephosphorylation. The same tyrosines are important for the GH-induced tyrosine phosphorylation and the transcriptional activation of Stat5 but are not essential for Stat3 activation. Using an in vitro approach with glutathion-S-transferase (GST)-fusion proteins, we demonstrate the recruitment of Stat5 by the C-terminal region of GHR through an interaction between the $\mathrm{SH} 2$ domain of Stat 5 and the phosphorylated tyrosine residues of the receptor. These data strongly suggest that separate regions of the GHR can mediate the recruitment of different Stat proteins regulating distinct signaling pathways.

\section{RESULTS}

\section{Characterization of Stable Chinese Hamster Ovary (CHO) Clones Expressing Mutant Forms of GHR}

To analyze the functional domains of GHR involved in the JAK/Stat pathways, we designed several mutant forms of the receptor (Fig. 1A). Two carboxy-terminal deletion mutants lacking the last $80(\Delta 540)$ and 166 residues $(\Delta 454)$, respectively, were constructed. Two
A.

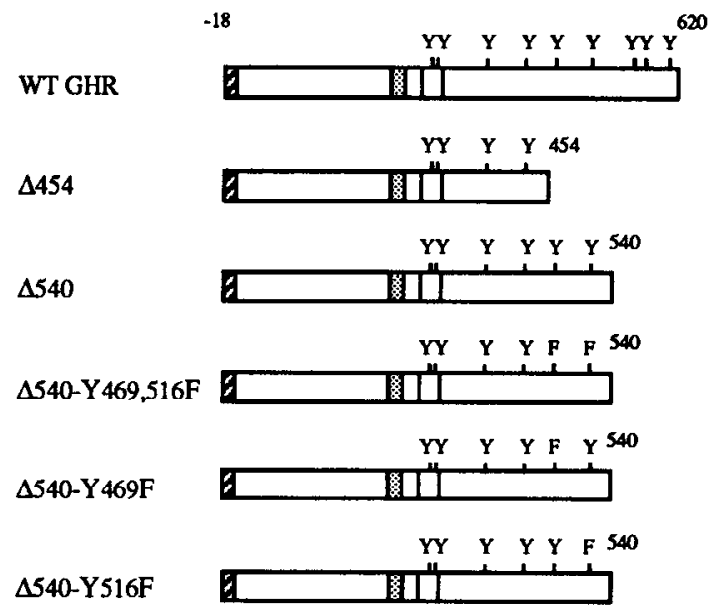

B.

\begin{tabular}{llr}
\hline $\begin{array}{c}\text { GH receptor } \\
\text { form }\end{array}$ & $\begin{array}{c}\mathrm{Kd} \\
(\mathrm{nM})\end{array}$ & Sites/cell \\
\hline $\mathrm{WT}$ & 0.45 & 90,000 \\
$\Delta 454$ & 0.35 & 110,000 \\
$\Delta 540$ & 0.33 & 100,000 \\
$\Delta 540-\mathrm{Y} 469,516 \mathrm{~F}$ & 0.12 & 110,000 \\
\hline
\end{tabular}

Fig. 1. Construction and Expression of Mutated Forms of Rabbit GHR

A, Schematic representation of wild type (WT) and mutated forms of rabbit GHR. Mutant forms of the receptor are shown below the WT; numbers indicate amino acid (aa) residues. Residue 1 is the first aa of the mature protein. Boxes 1 and 2 are indicated as solid lines, the signal peptide sequence as a hatched rectangle, and the transmembrane domain as a stippled rectangle. The tyrosine residues substituted with phenylalanine are indicated. $\mathrm{B}, \mathrm{GH}$-binding properties of stable $\mathrm{CHO}$ clones expressing WT or mutant GHR. The binding of $\left[{ }^{125}\right] \mathrm{hGH}$ to intact cells was measured in the presence of increasing concentrations of unlabeled $\mathrm{hGH}$. Dissociation constants $\left(K_{d}\right)$ and receptor numbers (sites per cell) were calculated by Scatchard analysis.

tyrosines are present in the cytoplasmic domain of the rabbit GHR unique to $\Delta 540$, at positions 469 and 516 . To study the importance of these tyrosine residues in GHR signaling, mutants were constructed in which tyrosines 469 and/or 516 were substituted with phenylalanine in $\triangle 540 \mathrm{GHR}$.

$\mathrm{CHO}$ cells were stably transfected with wild type (WT), $\Delta 454, \Delta 540$, and $\Delta 540-Y 469,516 \mathrm{~F}$ forms of GHR. Binding studies and Scatchard analysis (Fig. 1B) indicate that all mutant receptors are expressed at the cell surface with a comparable number of sites and show the similar binding affinities for human (h) GH. The size of the receptors and their ability to become tyrosine phosphorylated after $\mathrm{GH}$ stimulation were determined in different $\mathrm{CHO}$ clones stimulated with bi- 
A.
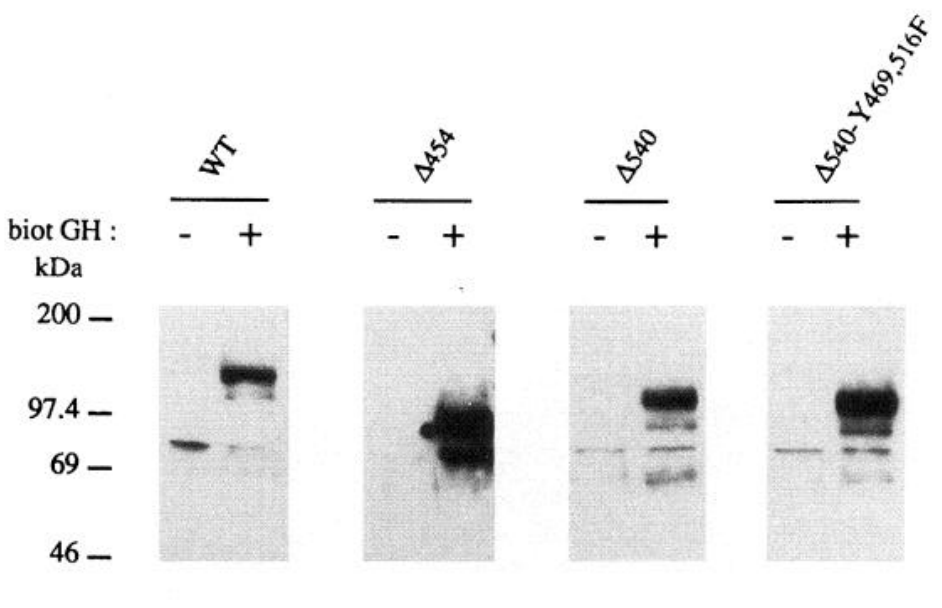

Probed with anti-GHR

B.
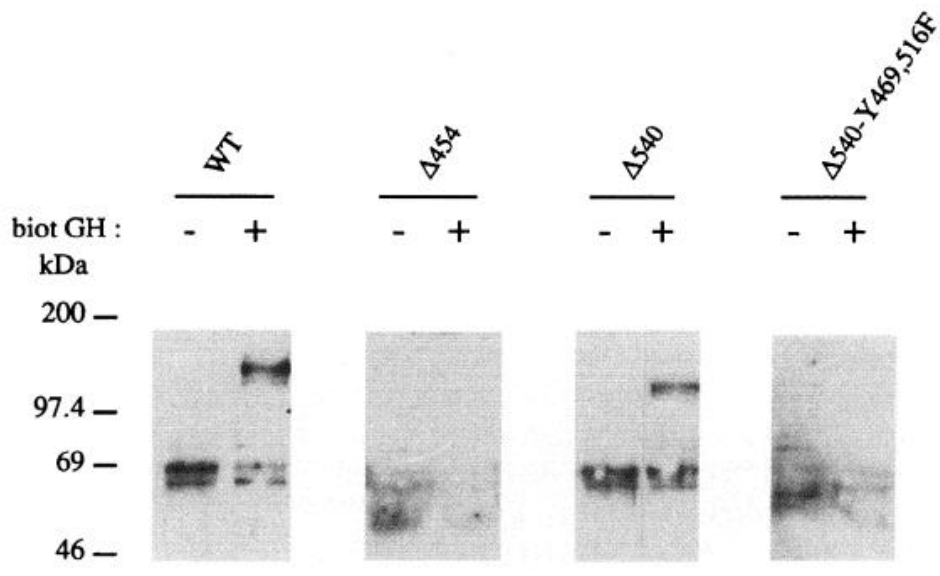

Probed with anti-PTyr

Fig. 2. Tyrosine Phosphorylation of WT and Mutant Forms of GHR

Stable $\mathrm{CHO}$ clones were stimulated (+) or not (-) with $20 \mathrm{~nm}$ biotinylated hGH for $5 \mathrm{~min}$, and the GH/GHR complexes were purified using streptavidin agarose. Western blot analysis was performed with anti-GHR antibody (A) or with anti-PTyr antibody (B). The molecular masses are indicated on the left.

otinylated $\mathrm{hGH}$. The complexes formed were precipitated with streptavidin beads and analyzed by Western blot. Immunoblotting with an anti-GHR antibody revealed molecular masses for the WT, $\Delta 454$, $\Delta 540$, and $\Delta 540-Y 469,516 \mathrm{~F}$ receptors, of 120,95 , 110 , and $110 \mathrm{kDa}$, respectively (Fig. 2A). The smaller molecular mass bands probably correspond to degradation products of GHR. Western blot analysis using anti-PTyr antibody detected phosphorylated proteins only in cell lines expressing WT and $\Delta 540$ receptors (Fig. 2B). These bands correspond in size to the WT and $\Delta 540$ receptors, suggesting their identity. In the other stable clones, we did not detect any phosphorylated proteins. We therefore conclude that tyrosine residues 469 and 516 are two major phosphorylation sites of GHR.

\section{The C-Terminal Tyrosine Residues of GHR Are Involved in JAK2 Dephosphorylation}

The activation of the associated tyrosine kinase JAK2 is one of the first steps of GHR signal transduction. As JAK kinases phosphorylate Stat proteins, the study of JAK2 phosphorylation is important for the understanding of the JAK/Stat signaling by GHR. We compared the kinetics of phosphorylation of JAK2 in the various stable clones expressing the mutant forms of GHR (Fig. 3A). The amount of immunoprecipitated JAK2 in each lane was evaluated by reprobing the membrane with anti-JAK2 antibody. The amount of phosphorylated JAK2 vs. the amount of immunoprecipitated JAK2 was quan- 
A.
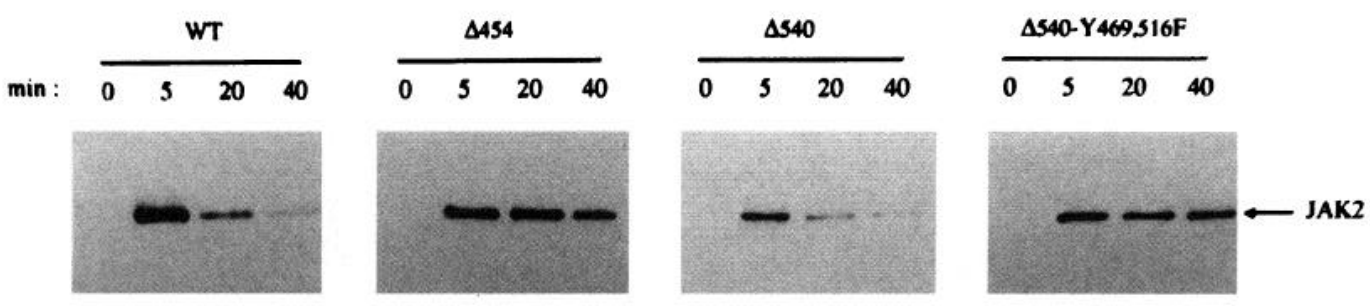

Probed with anti-PTyr
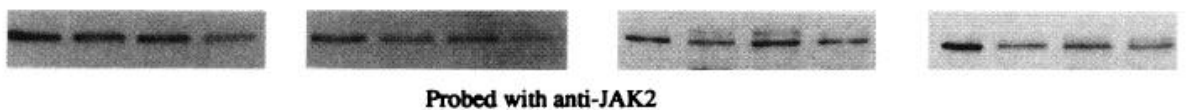

Probed with anti-JAK2

B.

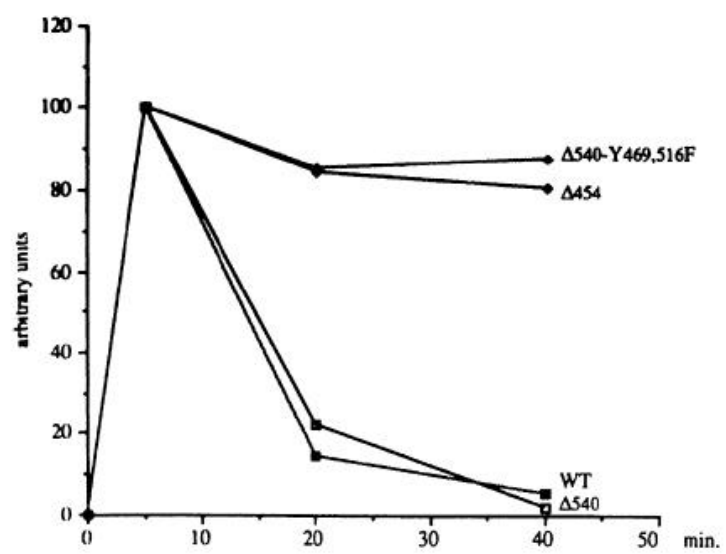

C.

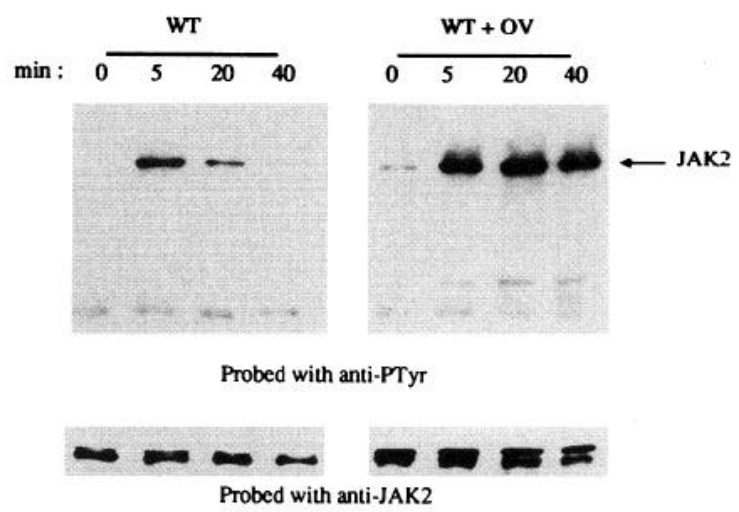

Fig. 3. Kinetics of Tyrosine Phosphorylation of JAK2 in CHO Cells Expressing WT and Mutant Forms of GHR

A, Cells were stimulated with $20 \mathrm{~nm}$ hGH for $0,5,20$, or $40 \mathrm{~min}$. Whole cell lysates were immunoprecipitated with anti-JAK2 antibody and analyzed by Western blot with anti-PTyr or anti-JAK2 antibody. B, Quantification of the relative extent of JAK2 phosphorylation after GH stimulation. The amount of tyrosine-phosphorylated JAK2, as assayed by densitometric scanning (arbitrary units), was normalized to the similarly quantitated amount of JAK2 recovered in each precipitate. C, Effect of orthovanadate on JAK2 phosphorylation. $\mathrm{CHO}$ cells expressing the WT receptor were preincubated for $1 \mathrm{~h}$ with $1 \mathrm{~mm}$ orthovanadate $(\mathrm{OV})$ and then were treated as described in panel $\mathrm{A}$.

tified using densitometry; the results are shown in Fig. 3B. In cell lines expressing WT and $\Delta 540$ receptors, tyrosine phosphorylation of JAK2 is transient with a peak at $5 \mathrm{~min}$ of stimulation after which phosphorylation declines. In contrast, in cell lines expressing $\Delta 454$ and $\Delta 540-Y 469,516 \mathrm{~F}$, phosphorylation of JAK2 is persistent, and no decrease is observed even at $40 \mathrm{~min}$. These observations strongly suggest that tyrosine residues 469 and/or 516 are involved in the recruitment or the activation of a tyrosine phosphatase. To support this hypothesis, cells expressing WT receptors were preincubated with orthovanadate for $1 \mathrm{~h}$ before the analysis of JAK2 phosphorylation (Fig. 3C). Under such conditions, the tyrosine phosphorylation of JAK2 was also sustained.

\section{The C-Terminal Domain of GHR Is Not Essential for Stat3 Activation by GH}

To study the activation of Stat3 by GH, two different approaches were used. Since tyrosine phosphorylation of Stat proteins is essential for their activity, we first analyzed the GH-induced phosphorylation of Stat3. A functional assay was then developed to measure the transcriptional activity mediated by Stat3 under GH stimulation. For this purpose, a reporter gene containing three copies of $\mathrm{m} 67$ (high-affinity mutated form of SIE) coupled to the thymidine kinase (TK) minimal promoter and the luciferase gene was constructed.

GH-induced tyrosine phosphorylation of Stat3 was analyzed in $\mathrm{CHO}$ cell lines stably expressing the WT or 
A.

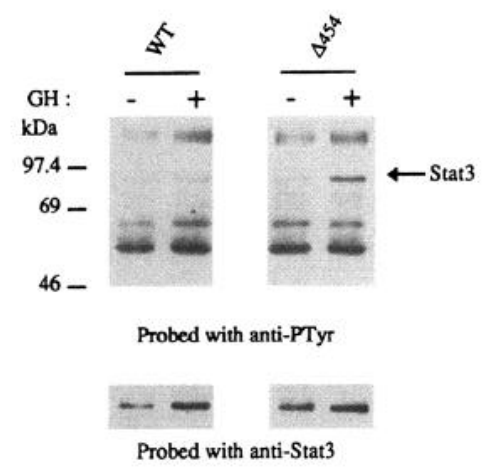

B.

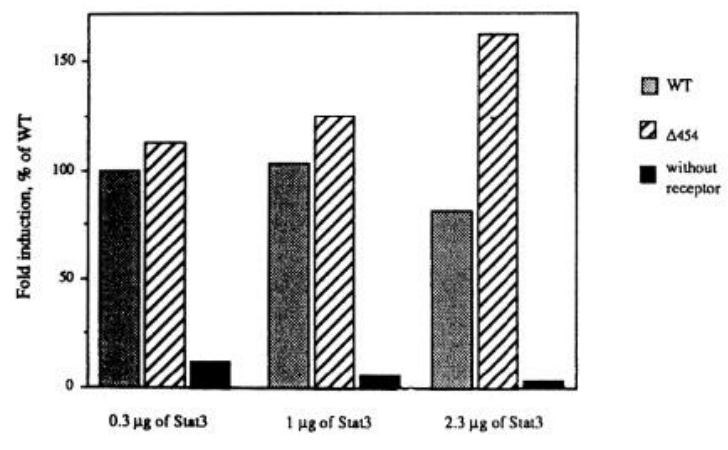

C.

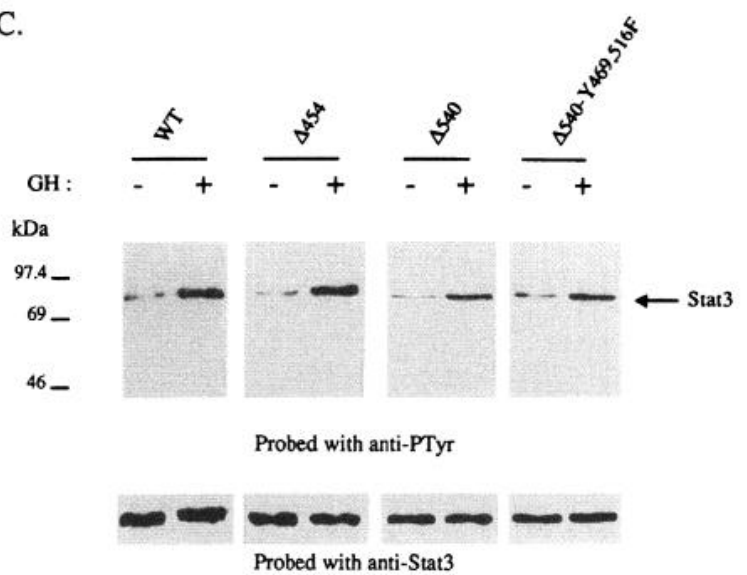

D.

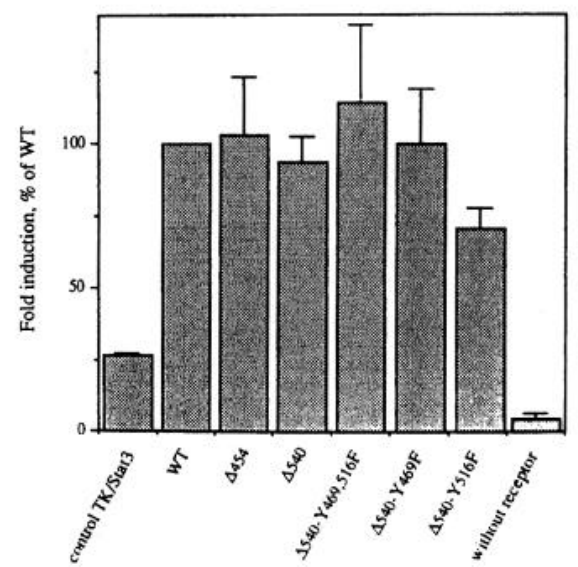

Fig. 4. GH-Induced Tyrosine Phosphorylation and Transcriptional Activity of Stat 3 in $\mathrm{CHO}$ and 293 Cells Expressing WT and Mutant Forms of GHR

A, Stable $\mathrm{CHO}$ clones expressing WT or $\Delta 454$ receptor were stimulated (+) or not (-) with $20 \mathrm{nM} \mathrm{hGH}$ for 15 min, and whole cell extracts were immunoprecipitated with anti-Stat3 antibody. Western blot analysis was performed with anti-PTyr or anti-Stat3 antibody. Molecular masses of the protein standards are indicated on the left. The arrow indicates the migration of endogenous Stat3 protein. B, CHO clones cotransfected with m67-TK-luc, different amounts $(0.3-2.3 \mu \mathrm{g})$ of Stat3 expression vector, and $\mathrm{pCH} 110$ were incubated in the presence of $50 \mathrm{~nm} \mathrm{hGH}$ and $250 \mathrm{~nm}$ dexamethasone or $250 \mathrm{~nm}$ dexamethasone alone. Cell extracts were prepared and assayed for luciferase and $\beta$-galactosidase activities, and the values for luciferase activity were normalized to $\beta$-galactosidase activity for each transfection experiment. The fold induction was calculated as normalized luciferase activity in the presence of both hormones divided by luciferase activity in the presence of dexamethasone alone. Results of a representative experiment are expressed as percent of WT. C, 293 cells were cotransfected with $2 \mu \mathrm{g} \mathrm{GHR,} 2 \mu \mathrm{g} \mathrm{Stat} 3$, and 0.05 $\mu \mathrm{g}$ JAK2 expression vectors. Forty eight hours after transfection, cells were stimulated $(+)$ or not $(-)$ with 20 nM hGH for 15 min. Cell lysates were immunoprecipitated with anti-Stat3 antibody and then subjected to Western blot analysis using anti-PTyr or anti-Stat3 antibody. The arrow indicates the migration of Stat3 protein. D, Stat3-mediated transcriptional activation induced by GH in 293 cells expressing WT and mutant forms of GHR. 293 cells cotransfected with GHR and Stat3 expression vectors, m67-TK-luc reporter gene, and pCH110 were incubated in the presence of $50 \mathrm{~nm} \mathrm{hGH}$ and $250 \mathrm{~nm}$ dexamethasone or $250 \mathrm{~nm}$ dexamethasone alone. Control transfections were performed without receptor expression vector or using TK-luc reporter gene. Cell extracts were prepared and assayed for luciferase and $\beta$-galactosidase activities; the values for luciferase activity were normalized to $\beta$-galactosidase activity for each transfection experiment. The fold induction was calculated as normalized luciferase activity in the presence of both hormones divided by luciferase activity in the presence of dexamethasone alone. Results are expressed as percent of WT and represent the mean (SEM) of three to five independent experiments.

$\Delta 454$ receptors. After $\mathrm{GH}$ stimulation, cell lysates were immunoprecipitated with anti-Stat3 antibody, and Western blot analysis was performed with anti-PTyr or anti-Stat3. In $\mathrm{CHO}$ cells expressing $\Delta 454$ receptor, a $\mathrm{GH}$-induced tyrosine phosphorylation of endogenous Stat3 was detected. In contrast, we failed to detect any induced phosphorylation of Stat3 in $\mathrm{CHO}$ cells expressing WT receptor (Fig. 4A), suggesting that the amount of phosphorylated endogenous Stat3 was below the detection limit of the antibodies used. In the same cells, transcriptional studies revealed that both WT and $\Delta 454$ receptors are able to activate additional 


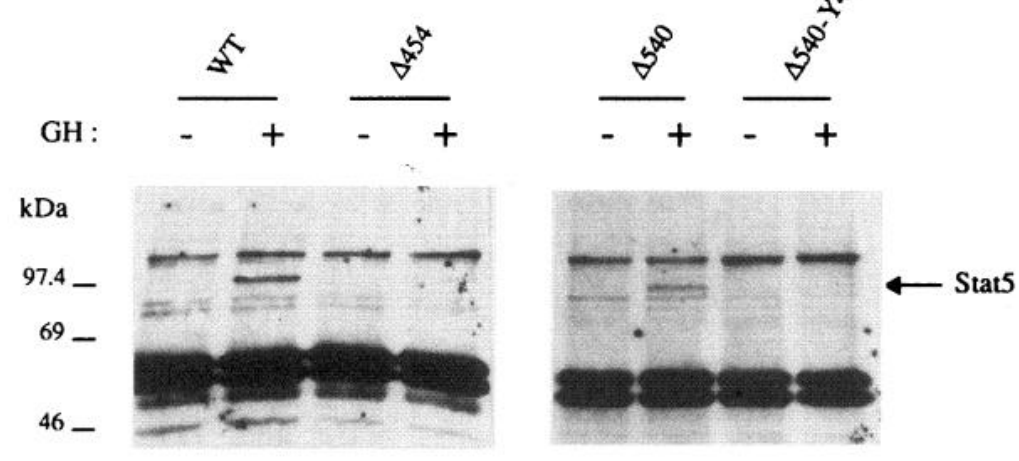

IP anti-PTyr, probed anti-Stat5

Fig. 5. Tyrosine Phosphorylation of Endogenous Stat5 Induced by GH in CHO Cells Expressing WT or Mutant Forms of GHR Cells were stimulated (+) or not (-) with $20 \mathrm{~nm} \mathrm{hGH}$ for $15 \mathrm{~min}$, and whole cell extracts were immunoprecipitated with anti-PTyr antibody. Western blot analysis was performed with anti-Stat5 antibody. Molecular masses of the protein standards are indicated on the left. The arrow indicates the migration of Stat5 protein.

exogenous Stat3. Moreover, when $2.3 \mu \mathrm{g}$ Stat3 cDNA were transfected, the transcriptional activity measured in cells expressing $\Delta 454$ receptor was significantly higher $(153 \pm 7.3 \%$ of WT, three independent experiments) (Fig. 4B). The greater phosphorylation and activation of Stat 3 in $\mathrm{CHO}$ cells expressing $\Delta 454$ receptor is consistent with the increased DNA-binding activity of Stat3 previously observed (15) and could be correlated to the sustained activation of JAK2 or to the absence of a negative regulatory domain within the receptor.

To detect a Stat3 tyrosine phosphorylation signal for the WT receptor, we used a transient overexpression cellular system consisting of 293 cells transfected with the various forms of GHR, Stat3, and JAK2 expression vectors. A similar level of expression of the different receptor forms at the cell surface was checked by binding experiments (data not shown). After GH stimulation for $15 \mathrm{~min}$, cell lysates were immunoprecipitated with anti-Stat 3 antibody, and Western blot analysis was performed with anti-PTyr or anti-Stat3. In cells expressing either of four forms of GHR, a clear induction of Stat3 tyrosine phosphorylation was detected upon GH stimulation (Fig. 4C, upper pane/). The amount of Stat3 protein present in the lysates from stimulated or unstimulated cells was equivalent as determined after reprobing the membrane with an anti-Stat3 antibody (Fig. 4C, lower pane/). Transcriptional studies carried out in 293 cells transfected with cDNAs encoding GHR forms, Stat3, and the reporter construct (Fig. 4D) showed a significant GH-dependent transcriptional activation with all receptors $(100 \%$ representing 5 -fold induction for the WT receptor). In contrast, little or no activation was measured without receptor or when a control TK-luciferase reporter gene was used. The overexpression system and the sensitivity of the reporter construct used can explain the similar results obtained for WT and $\Delta 454$ receptors in
293 cells in comparison to the observations in the $\mathrm{CHO}$ system.

Taken together, these results show that the C-terminal portion (residues 455-620) of the GHR is not essential for $\mathrm{GH}$-induced tyrosine phosphorylation and transcriptional activation of Stat3.

\section{The C-Terminal Tyrosine Residues of Rabbit GHR Are Required in Stat5 Activation by GH}

We studied the GH-dependent tyrosine phosphorylation of Stat5 and its functional activation. To evaluate the transcriptional activity mediated by Stat5, two reporter genes were constructed. In one, the LHRE was fused to the TK promoter and the luciferase gene. LHRE is an element of the $\beta$-casein promoter that was used for the affinity purification of Stat5 (17). In the second reporter gene, the GHREII was fused to TK and luciferase. GHREII is a GHregulated element of the Spi 2.1 promoter that binds Stat5 (8). Using this approach, we were able to obtain information on the role of Stat5 in the transcriptional regulation of genes such as Spi 2.1 and $\beta$-casein.

We analyzed the ability of GH to induce phosphorylation of endogenous Stat5 in $\mathrm{CHO}$ cell lines stably expressing the WT and the mutant forms of the receptor. Immunoprecipitation with anti-PTyr antibody followed by Western blot analysis with anti-Stat5 antibody were performed. As shown in Fig. 5, GH-induced phosphorylation of Stat5 is detected only in cells expressing WT or $\Delta 540$ receptor. No phosphorylation of Stat 5 was detected in cells expressing $\Delta 454$ or $\Delta 540$ $\mathrm{Y} 469,516 \mathrm{~F}$ receptor, suggesting that the receptor domain between residues 455 and 540 (in particular tyrosines 469 and/or 516) is important for Stat5 tyrosine phosphorylation upon GH stimulation. 


\section{A. LHRE REPORTER GENE}
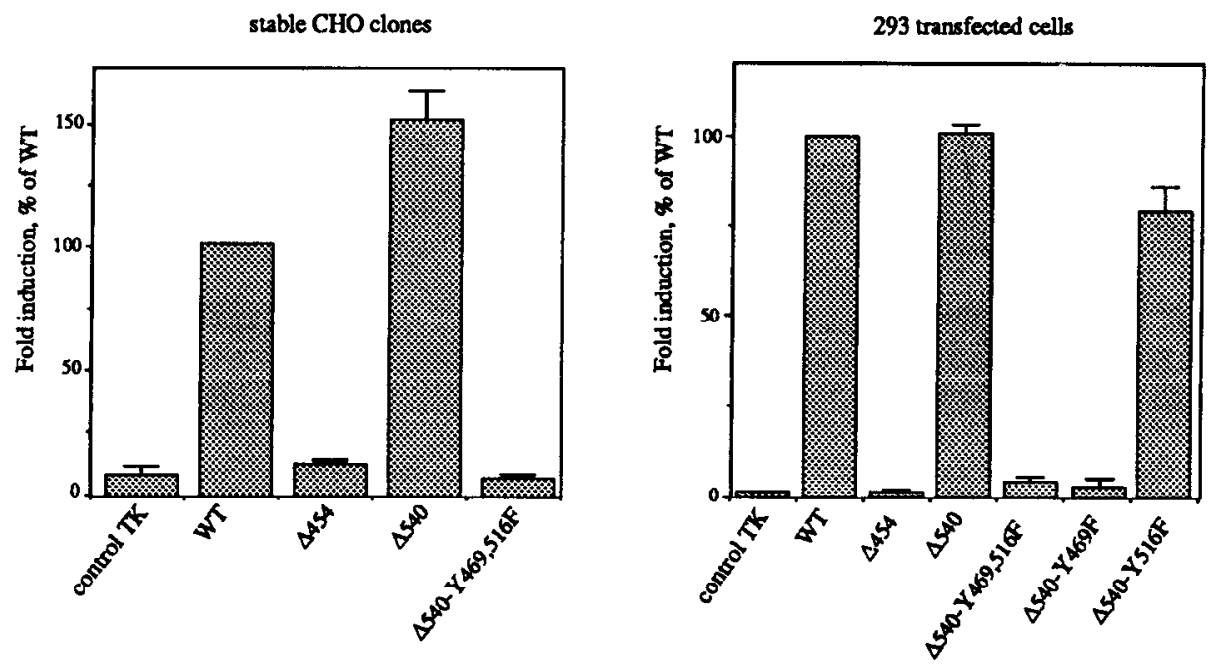

\section{B. GHREII REPORTER GENE}
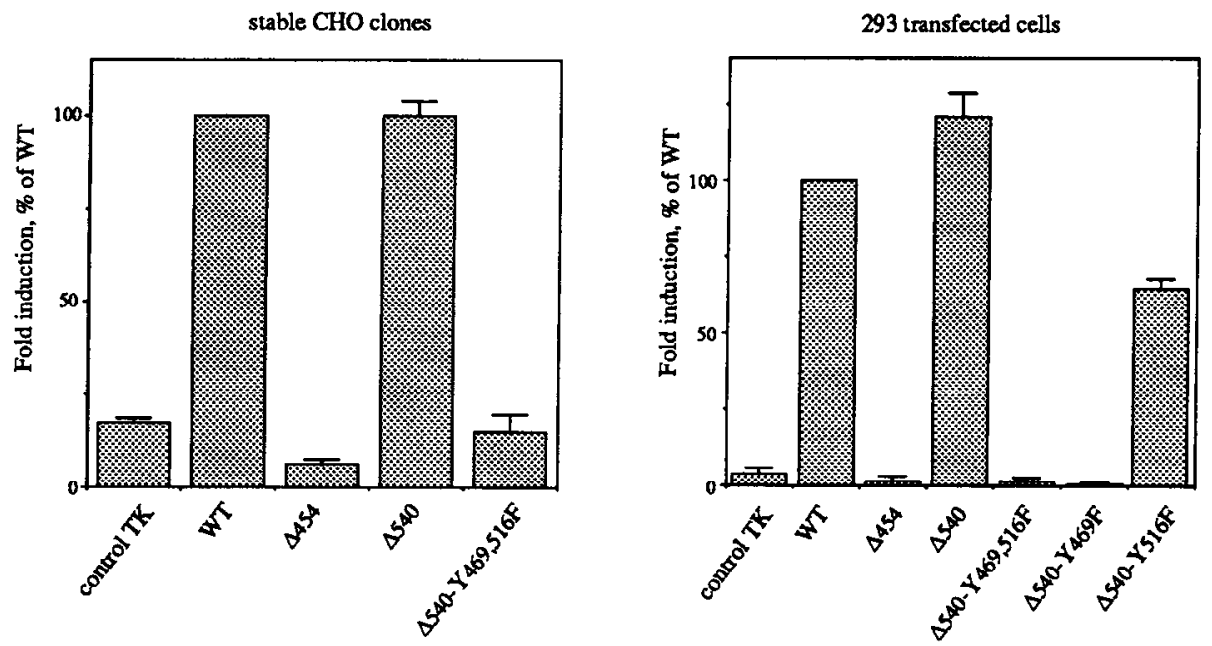

Fig. 6. Stat5-Mediated Transcriptional Activation Induced by GH in $\mathrm{CHO}$ or 293 Cells Expressing WT or Mutant Forms of GHR

Cells cotransfected with GHR cDNA (for 293 cells only), LHRE-TK-luc (A), or GHREII-TK-luc (B) reporter gene and pCH 110 were incubated in the presence of $50 \mathrm{nM} \mathrm{hGH}$ and $250 \mathrm{nM}$ dexamethasone or $250 \mathrm{nM}$ dexamethasone alone. Control transfections were performed using TK-luc reporter gene. Cell extracts were prepared and assayed for luciferase and $\beta$-galactosidase activities, and the values for luciferase activity were normalized to $\beta$-galactosidase activity for each transfection experiment. The fold induction was calculated as normalized luciferase activity in the presence of both hormones divided by luciferase activity in the presence of dexamethasone alone. Results are expressed as percent of WT and represent the mean (SEM) of three to five independent experiments.

GH-induced transcriptional activation of both reporter constructs (LHRE and GHREII) was measured in two different cellular systems. Stable $\mathrm{CHO}$ clones expressing the various forms of GHR were transfected with the two reporter genes; 293 cells were transiently cotransfected with the GHR mutant expression vectors and the reporter constructs. As shown in Fig. 6, transcriptional activation through LHRE or GHREII is observed in $\mathrm{CHO}$ cells expressing WT or $\Delta 540$ receptor $(100 \%$ representing 8 -fold induction for the WT receptor with LHRE reporter gene and 5 -fold induction with GHREll reporter gene) but not in $\mathrm{CHO}$ cells expressing $\Delta 454$ or $\Delta 540-Y 469,516 \mathrm{~F}$ receptor. Similar results were observed in transfected 293 cells $(100 \%$ representing 13-fold induction for the WT receptor with LHRE reporter gene and 7-fold induction with GHREIl reporter gene). Moreover, the single tyrosine mutant $\Delta 540-Y 469 \mathrm{~F}$ failed to transactivate either reporter construct in 293 cells, while the $\Delta 540-Y 516 \mathrm{~F}$ mutant was able to induce transcription. These results 


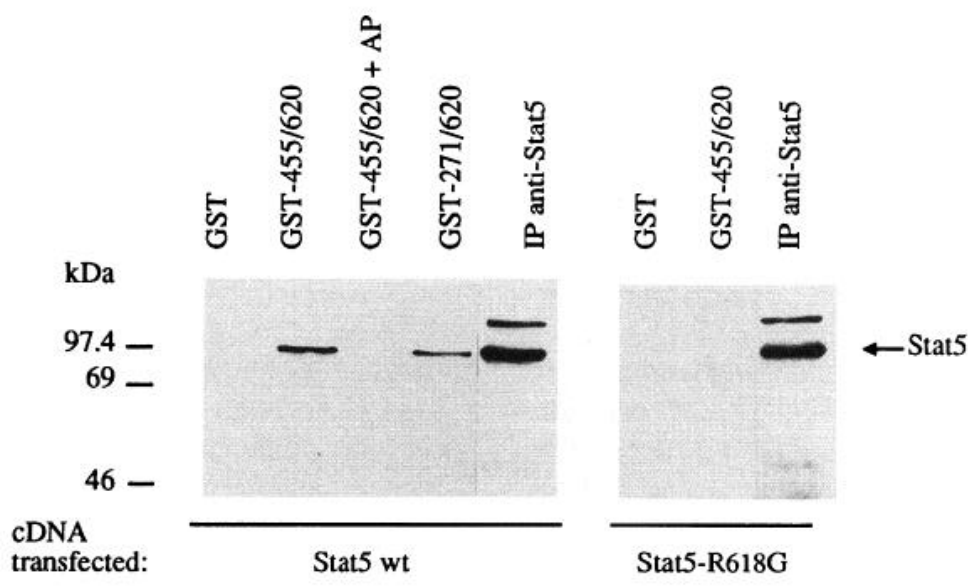

Probed with anti-Stat5

Fig. 7. In Vitro Studies

Association of Stat5 with the C-terminal-phosphorylated residues of GHR. 293 cells were transfected with wild type Stat5 (wt) or Stat5-R618G expression vectors. Cell lysates were incubated with phosphorylated GST-fusion proteins containing the C-terminal region of GHR (GST-455/620) or the entire intracellular domain (GST-271/620) or with GST-455/620 protein dephosphorylated by alkaline phosphatase (GST-455/620 + AP). GST protein was used as a control. To control the amount of Stat5 wt or Stat5-R-618G expressed, cell lysates were immunoprecipitated with anti-Stat5 antibody. The complexes formed were then analyzed by Western blot with anti-Stat5 antibody. The molecular masses of the protein standards are indicated on the left. The arrow indicates the migration of Stat5 proteins.

demonstrate that, in the context of $\Delta 540 \mathrm{GHR}$, tyrosine residue 469 is required for Stat5-mediated transcription induced by $\mathrm{GH}$.

\section{The SH2 Domain of Stat5 Binds the C-Terminal Phosphorylated Tyrosines of GHR}

An in vitro approach was developed to study the putative interactions between Stat3, Stat5, and the cytoplasmic residues of the GHR. Different GST-fusion proteins containing the $\mathrm{C}$-terminal region of $\mathrm{GHR}$, from residues $455-620$ (GST-455/620), the entire cytoplasmic domain of the receptor (GST-271/620), or GST alone, were produced in bacteria in which phosphorylation of tyrosines occurs. Lysates of 293 cells, transfected with Stat5 or Stat3 expression vectors, were incubated with $2 \mu \mathrm{g}$ of the various GST fusion proteins attached to glutathione beads. Western blot analyses using anti-Stat5 or anti-Stat3 antibodies were performed to detect the association of Stat 5 or Stat 3 with the GST fusion proteins.

Stat5 was detected on GST-455/620 beads, but not on GST beads (Fig. 7), showing a specific interaction of Stat5 with the C-terminal region of the receptor. After pretreatment of the GST-455/620 beads with alkaline phosphatase, no Stat5 was detected, suggesting the involvement of phosphorylated tyrosine residues of the receptor in this interaction. As expected, Stat5 also associated with the entire intracellular domain of the GHR (GST-271/620).

Transfection experiments of 293 cells with an expression vector encoding a point mutant of Stat5 in which the conserved arginine residue of the SH2 domain was changed into glycine (Stat5-R618G) were performed, and, in this case, no interaction with GST455/620-phosphorylated fusion protein was detected. We verified that both wild type Stat5 and Stat5-R618G were expressed at comparable levels: the same amount of protein was detected by Western blot using anti-Stat5 antibody after immunoprecipitation with anti-Stat5 in cells transfected with both cDNAs. The higher molecular mass band represents a nonspecific interaction of the antibodies used.

Taken together, these data demonstrate that the Stat5/GHR interaction is mediated by the $\mathrm{SH} 2$ domain of Stat5 and the phosphorylated tyrosines of the receptor.

Using the same approach, we were not able to detect any specific interaction between Stat 3 and the cytoplasmic domain of GHR: Stat3 bound to the GST protein alone, as well as to GST-455/620 and GST$271 / 620$ proteins (data not shown).

\section{DISCUSSION}

JAK kinases and Stat transcription factors have been shown to participate in the intracellular signaling of cytokine receptors. In particular, GHR associates with the JAK2 tyrosine kinase and activates Stat1, Stat3, and Stat5 transcription factors. Genetic experiments or analysis of genetic defects in humans (18-20), as well as the studies with dominant negative mutants of JAK kinases (21), suggest that most pathways induced by cytokine receptors are dependent on JAK kinases. Among these pathways, the involvement of JAK tyrosine kinases in Stat protein activation has been well 
established. The use of mutant forms of cytokine receptors allowed identification of regions important for JAK kinase activation that were absolutely essential for Stat activation $(22,23)$. Furthermore, in vitro experiments directly demonstrated a tyrosine phosphorylation of in vitro transcribed and translated Stat5 by JAK2 kinase (24). However, the role of Stat proteins in cytokine-induced responses is not completely understood. In some cases, the activation of Stat proteins could be linked with ligand-induced proliferation and, in other cases, there is a divergence between Stat activation and proliferation. For example, the membrane-proximal region of the $\beta_{c}$-chain of the interleukin-3 receptor is sufficient for Stat5 activation and DNA synthesis (25). In contrast, the $\mathrm{C}$-terminal region of the interleukin-2 receptor is necessary for Stat5 activation but not for ligand-induced proliferation (26).

We and others have identified different functional regions in the cytoplasmic domain of GHR. The membrane-proximal region of the receptor, containing the proline-rich conserved motif (Box 1), is essential and sufficient for $\mathrm{GH}$-induced activation of JAK2, proliferation, and activation of some Stat proteins $(22,27,28)$. In contrast, transcriptional activation of $\mathrm{GH}$-induced genes, including Spi $2.1(16,29)$ and the insulin gene (30), requires additional C-terminal sequences of the GHR. Many GH-responsive promoters and, in particular, those of Spi 2.1, $\beta$-casein, and c-fos genes, contain Stat-binding sequences. To characterize the molecules and the residues of the receptor involved in $\mathrm{GH}$-induced transcription, we have analyzed the JAK Stat pathways. In preliminary studies, two C-terminal regions (from residues $455-540$ and $541-620$ ) were found to be involved in transcriptional activation of Spi 2.1 or $\beta$-casein promoter by $\mathrm{GH}$ (our unpublished data). In the present paper, we focused on one of these functional domains: the cytoplasmic region between residues 455 and 540 . As tyrosine residues can be essential for the recruitment of $\mathrm{SH} 2$-containing signaling molecules, the two tyrosines present in this region (Y469 and $Y 516$ ) were mutated to phenylalanine. As shown in the experiments using biotinylated $\mathrm{GH}$, one or both of these tyrosines are phosphorylated after $\mathrm{GH}$ stimulation and constitute major sites of phosphorylation.

The phosphorylation of JAK2 kinase was analyzed in several cell lines expressing WT or mutant forms of GHR. Our results suggest that tyrosine residues 469 and/or 516 of GHR are involved in the activation of a tyrosine phosphatase that could dephosphorylate JAK2 and permit the down-regulation of the GH response in cells. In the same cellular system, a low level of JAK1 phosphorylation induced by $\mathrm{GH}$ was detected, and the C-terminal region of the receptor seemed to be involved in JAK1 down-regulation as well (our unpublished data). For several members of the cytokine receptor superfamily (erythropoietin, interleukin-3, interferon $\alpha / \beta$ receptors), phosphatase molecules have been implicated in their signaling pathways. Recently, phosphatase PTP1D has been reported to be recruited by the PRL receptor and to positively regulate gene-specific transcription (34). The identification of the phosphatase involved in $\mathrm{GH}$ signaling is currently under investigation. The involvement of tyrosine phosphatase in GHR signaling could participate in the regulation of Stat protein activity by modulating JAK kinase phosphorylation and activation.

To study the activation of Stat transcription factors by $\mathrm{GH}$, we developed a functional approach that allows us to analyze the transcriptional activity of Stat proteins other than, and not limited to, their ability to bind a DNA target sequence as in gel shift experiments. The results obtained with these reporter gene constructs clearly showed that different regions of the receptor are required for the $\mathrm{GH}$-induced activation of Stat3 and Stat5.

In previous studies, we have shown that $\mathrm{GH}$ induces DNA-binding activity of Stat 3 in $\mathrm{CHO}$ cells expressing C-terminal-deleted receptors (from residues 455-620) (15). We now present evidence that this region is essential neither for tyrosine phosphorylation of Stat3 nor for Stat3-mediated transcription induced by GH. For other cytokine receptors, it has been reported that Stat3 is recruited via tyrosine residues of their cytoplasmic domain, and the consensus sequence $Y X X Q$ present in gp130 has been proposed as a specific motif for Stat3 recruitment (35). This motif is not present in the GHR. Mutants of granulocyte colonystimulating factor receptor lacking this particular sequence are still able to activate Stat3 (23). Here, we demonstrate that the carboxy-terminal tyrosines (469 and 516) are not required for Stat3 activation. Results from other groups showed that a truncated GHR mutant, lacking all cytoplasmic tyrosine residues, was still able to activate Stat-binding activity to SIE and $\gamma$-responsive region probes that essentially bind Stat 1 or Stat3 $(36,37)$. Taken together, these observations suggest that tyrosine residues of GHR are not essential for the activation of some Stat proteins and, in particular, Stat3. However, the consensus motif $(Y X X Q)$ is present in the sequence of JAK2, and we propose that Stat3 could be recruited by this GHRassociated kinase. This model is supported by recent results of Gupta et al. (38) showing that Stat1 and Stat2 could directly interact with JAK kinases. Such a hypothesis could explain the higher levels of Stat3 tyrosine phosphorylation and transcriptional activation observed in the $\mathrm{CHO}$ cell lines expressing $\Delta 454$. This could be due in part to the sustained phosphorylation of JAK2 and would be consistent with a possible enhancement of Stat3 recruitment by JAK2. However, although the use of truncation mutants of GHR suggests that the C-terminal region of GHR is not essential for Stat3 activation, a putative interaction of Stat3 with this region cannot be excluded in the context of the full-length receptor.

In contrast, the C-terminal residues (455-540) of GHR are essential for Stat5 activation. Phosphorylation studies in stable $\mathrm{CHO}$ clones showed that ty- 
rosines 469 and/or 516 of the receptor were required for $\mathrm{GH}$-induced phosphorylation of Stat5. As one or both tyrosines are phosphorylated upon GH stimulation, they could be important for the recruitment of Stat5 by GHR via the Stat5 SH2 domain. Using two reporter genes containing the LHRE and GHREIl elements, GH-induced transcription was observed in two cellular systems (CHO and 293 cells) expressing the full-length GHR. It has been reported that these two elements are able to bind only Stat5 and no other Stat proteins $(8,39)$; our results thus show that Stat5 is transcriptionally functional after $\mathrm{GH}$ stimulation. In COS cells transfected with GHR CDNA and a reporter construct containing a part of the $\beta$-casein promoter including a single Stat5 binding site, $\mathrm{GH}$ was able to induce DNA binding, but not transcriptional activity, of Stat5 (40). Differences in the cellular system and/or in the reporter gene could explain this discrepancy. The absence of Stat5-mediated transcriptional activity with $\Delta 454$ and $\Delta 540-Y 469,516 \mathrm{~F}$ mutants indicates a correlation between Stat5 phosphorylation and transcriptional activity. More precisely, we identified the specific tyrosine residue (tyrosine 469) essential for Stat5 activation in the context of $\Delta 540 \mathrm{GHR}$. This tyrosine is probably involved in Stat 5 recruitment. A cytoplasmic region of porcine GHR, containing the tyrosine residue homologous to Y469 in rabbit GHR, has been shown to be important for the $\mathrm{GH}$-induced tyrosine phosphorylation of a $95-\mathrm{kDa}$ protein that could be Stat5 (41). In addition, since mutants $\Delta 454$, $\Delta 540-Y 469,516 \mathrm{~F}$, and $\Delta 540-\mathrm{Y} 469 \mathrm{~F}$ of GHR were also unable to induce the transcription of the full-length promoters of Spi or $\beta$-casein genes upon GH stimulation (our unpublished data), a correlation can be established between the noninducibility of Spi or $\beta$-casein transcription and the lack of activation of Stat 5 by these mutant forms. Our data strongly suggest that Stat5 is crucial and absolutely required for both Spi and $\beta$-casein gene transcription induced by $\mathrm{GH}$.

In vitro experiments demonstrate an interaction between Stat5 and the phosphorylated tyrosines of the C-terminal domain of the receptor (GST-455/620). In addition, we clearly show that this association takes place between the $\mathrm{SH} 2$ domain of Stat5 and carboxyterminal phosphorylated tyrosines of GHR. For this purpose, a mutated form of Stat5 was used that contains a point mutation changing the absolutely conserved arginine in the floor of the $\mathrm{SH} 2$ phosphotyrosyl pocket to glycine.

Taken together, our data demonstrate that different domains of the GHR are essential in Stat3 and Stat5 recruitment and activation: the membrane-proximal region is sufficient for Stat3 activation, possibly because of the recruitment of Stat3 by JAK2, and the GHR C-terminal region is absolutely required for Stat5 recruitment through its tyrosine residues, leading to Stat5 activation. It has been shown that $\mathrm{GH}$ induces a short-term proliferation of BAF3 cells expressing mutant forms of GHR lacking the C-terminal tail (Ref. 22 and our unpublished data). In addition, transcription of
GH-specific genes (Spi 2.1 and $\beta$-casein) requires the carboxy-terminal region of the receptor. Thus, we suggest that Stat3 may be involved in proliferation pathways, whereas $S t a t 5$ could play a role in differentiation pathways and in gene-specific transcription.

\section{MATERIALS AND METHODS}

\section{Plasmids}

LHRE, GHREll, and m67 reporter genes were constructed using a Puc 18 vector containing the TK minimal promoter linked to luciferase reporter gene (TK-luc) (42). Double-stranded oligonucleotides, 5' -CTGCAGTCGACATTCCCGTAAATCGTC GACTGCA-3' for m67 (three copies) and 5'-CTGCAGTGTGGACTTCTTGGAATTAA GGGACTITTGCTGCAG-3' for LHRE (six copies) were inserted into the Pstl site of the vector. Three copies of GHREII (13) were subcloned between Sall/BamHI of the vector.

The cDNA encoding the $\triangle 454$-truncated mutant of rabbit GHR was previously described (16). The cDNA encoding $\triangle 540$ was constructed by $P C R$, using primers that permit the addition of an in-frame stop codon and was inserted in pcDNA3 expression vector (Invitrogen, San Diego, CA). Mutagenesis on single-stranded DNA was done by the method of Kunkel using the following oligonucleotides: 5'-ACTAACCTGGGCGAAAAAGTCGATGTITGC-3' for the substitution of tyrosine 469 to phenylalanine and $5^{\prime}$-CTGCTTCACAGAAGA-AGGCGTTGTCCATG-3' for the substitution of tyrosine 516 with phenylalanine.

The sequence encoding the $\mathrm{C}$-terminal region of rabbit GHR (residue 455-620) was amplified by PCR and subcloned in the BamHI site of pGEX-2TK (Pharmacia, Piscataway, NJ). The cDNA sequence encoding the entire cytoplasmic domain of GHR was cloned in pGEX-2T (Pharmacia) as described (43). The cDNA encoding sheep Stat5-R618G (subcloned in the expression vector $\mathrm{PXM}$ ) was constructed by mutagenesis on single-stranded DNA using the following oligonucléotide: 5'-TTGTTGGGCT TAGCGACTCA-3'.

\section{Cell Culture/Purification of GHR Complexes on Streptavin-Agarose/Immunoprecipitation}

Generation of stable $\mathrm{CHO}$ clones, transfection of 293 cells, binding assays, and cell culture conditions were performed as described $(15,16)$.

$\mathrm{CHO}\left(20 \times 10^{6}\right)$ cells were cultured in serum-free medium overnight and incubated with or without $20 \mathrm{~nm}$ biotinylated hGH for $5 \mathrm{~min}$ at $37 \mathrm{C}$. Cell proteins were extracted in $0.5 \mathrm{ml}$ lysis buffer (10 mM Tris- $\mathrm{HCl}, \mathrm{pH} 7.5,150 \mathrm{~mm} \mathrm{NaCl}, 5 \mathrm{~mm}$ EDTA, $10 \%$ glycerol, $0.5 \%$ Triton $X-100,30 \mathrm{~mm}$ Na pyrophosphate, $50 \mathrm{~mm} \mathrm{NaF}, 1 \mathrm{~mm} \mathrm{Na}$ orthovanadate, $1 \mu \mathrm{g} / \mathrm{ml}$ pepstatin, $2 \mu \mathrm{g} / \mathrm{ml}$ leupeptin, $5 \mu \mathrm{g} / \mathrm{ml}$ aprotinin, $1 \mathrm{~mm}$ phenylmethylsulfonylfluoride). Lysates were treated with steptavidin agarose as described (16) and subjected to $7.5 \%$ SDS-PAGE.

$\mathrm{CHO}\left(20 \times 10^{6}\right)$ or $293\left(10 \times 10^{6}\right)$ cells (transfected with 2 $\mu \mathrm{g} \mathrm{GHR}, 2 \mu \mathrm{g} \mathrm{Stat3}$, and $0.05 \mu \mathrm{g}$ JAK2 expression vectors) were cultured in serum-free medium overnight and stimulated with $20 \mathrm{nM} \mathrm{hGH}$ (kindly provided by Serono) for various time periods. Cells were lysed in $0.5 \mathrm{ml}$ lysis buffer and incubated with the designated antibody $(1 \mu \mathrm{g}$ anti-PTyr (4G10, UBI), $1 / 500$ of anti-JAK2 (UBI) or $1 \mu \mathrm{g}$ anti-Stat3 (Santa Cruz Biotechnology, Santa Cruz, CA). After treatment with protein A-Sepharose, lysates were subjected to $7.5 \%$ SDS-PAGE. 


\section{Western Blot}

After separation by gel electrophoresis, proteins were transferred to nitrocelluiose and subjected to immunoblot analysis. Membranes were incubated with the indicated antibody $(0.1 \mu \mathrm{g} / \mathrm{ml}$ anti-Ptyr (4G10, UBI, Lake Placid, NY), $1 / 4000$ of anti-JAK2 (UBI), 1/250 of anti-Stat5 (Transduction Laboratories, Lexington, $\mathrm{KY}), 0.2 \mu \mathrm{g} / \mathrm{ml}$ anti Stat3, or $0.5 \mu \mathrm{g} / \mathrm{ml}$ antiGHR (42) as described (16). Proteins were visualized using the enhanced chemiluminescence detection system (Amersham, Arlington Heights, IL). Membranes were dehybridized of probes overnight at $4 \mathrm{C}$ in an acid solution $(0.1 \mathrm{M}$ glycine, $\mathrm{pH} 3,0.1 \mathrm{M} \mathrm{NaCl}$ ) and reprobed with the indicated antibody.

\section{Transcription Assays}

Stable $\mathrm{CHO}$ clones were plated in six-well plates $\left(10^{6}\right.$ cells per well) and were transfected with $3 \mu \mathrm{g}$ TK-luc, LHRE/TKluc, or GHREII/TK-luc reporter genes and $6 \mu \mathrm{g} \mathrm{pCH} 110(\beta-$ galactosidase expression vector, Pharmacia) per plate. 293 cells in six-well plates $\left(0.5 \times 10^{6}\right.$ cells per well) were transfected with 0.2 to $1 \mu \mathrm{g}$ of a pcDNA3 expression vector containing the different mutant forms of GHR, $1.5 \mu \mathrm{g}$ TK-luc, LHRE/TK-luc, or GHREII/TK-luc and $2.5 \mu \mathrm{g} \mathrm{pCH110} \mathrm{per}$ plate. In experiments using m67/TK-luc reporter gene, $2 \mu \mathrm{g}$ Stat3 expression vector were cotransfected. Cells were incubated for $24 \mathrm{~h}$ with serum-free medium containing $50 \mathrm{~nm}$ $\mathrm{hGH}$ and $250 \mathrm{~mm}$ dexamethasone or $250 \mathrm{~mm}$ dexamethasone alone. Cells were lysed as described (16), and cell extracts were used for determination of luciferase and $\beta$-galactosidase activities. Luciferase activity was normalized to the $\beta$-galactosidase activity, and results are the mean (SEM) of three to five independent experiments done in triplicate.

\section{GST-Fusion Proteins}

Phosphorylated GST-fusion proteins were produced in Epicurian Coli TKB1 (Stratagene, La Jolla, CA), transformed with GST- $455 / 620$ or GST- $271 / 620$ constructs, as recommended by the manufacturer.

To dephosphorylate GST-fusion proteins, $2 \mu \mathrm{g}$ protein were incubated for $1 \mathrm{~h}$ at $30 \mathrm{C}$ with $10 \mathrm{U}$ calf intestine alkaline phosphatase (Boehringer Mannheim, Indianapolis, IN) in 20 mM HEPES, $\mathrm{pH} 7,150 \mathrm{~mm} \mathrm{NaCl}, 0,1 \%$ Triton $\mathrm{X}-100$, and $10 \%$ glycerol.

The 293 cells were cultured in $100-\mathrm{mm}$ dishes and transfected with $5 \mu \mathrm{g}$ Stat3, Stat5, or Stat5-R618G expression vectors. Cell lysates were prepared and incubated overnight at $4 \mathrm{C}$ with GST-fusion proteins bound to glutathione-Sepharose beads ( $2 \mu \mathrm{g}$ per assay). After washing the beads with lysis buffer, adsorbed proteins were subjected to $7.5 \%$ SDSPAGE and analyzed by Western blot.

The level of expression of wild type Stat5 and Stat5-R618G in 293 transfected cells was checked by immunoprecipitation of cell lysates with $1 \mu \mathrm{g}$ anti-Stat5 antibody (Santa Cruz Biotechnology) followed by Western blot analysis.

\section{Acknowledgments}

We thank James Darnell for kindly providing the Stat 3 cDNA; Bernd Groner, for the Stat5 cDNA; James Ihle, for the JAK2 CDNA; Alphonse Le Cam, for the GHREII/TK-CAT vector; and Michel Pons, for the Puc-18/TK-luc vector. We also acknowledge Joan Burnside and Patrick Mayeux for their helpful discussions and Claudine Coridun, who typed the manuscript.

Received February 8, 1996. Revision received April 18, 1996. Accepted April 24, 1996.
Address requests for reprints to: Joelle Finidori, Endocrinologie Moleculaire, Faculte de Medecine Necker-Enfants Malades, 156, rue de Vaugirard, 75730 Paris, Cedex 15 France.

\section{REFERENCES}

1. Leung DW, Spencer SA, Chachianes G, Hammonds RG, Collins C, Henzel WJ, Barnard R, Waters MJ, Wood WI 1987 Growth hormone receptor and serum binding protein: purification, cloning, and expression. Nature 330:537-543

2. Kelly PA, Djiane J, Postel-Vinay MC, Edery M 1991 The prolactin/growth hormone receptor family. Endocr Rev 12:235-251

3. Taniguchi T 1995 Cytokine signaling through nonreceptor protein tyrosine kinases. Science 268:251-255

4. Argetsinger LS, Campbell GS, Yang $X$, Witthuhn BA, Silvennoinen O, Ihle JN, Carter-Su C 1993 Identification of Jak2 as a growth hormone receptor-associated tyrosine kinase. Cell 74:237-244

5. Ivashkiv LB 1995 Cytokines and stats: how can signals achieve specificity? Immunity $3: 1-4$

6. Meyer DJ, Campbell GS, Cochran BH, Argetsinger LS, Larner AC, Finbloom DS, Carter-Su C, Schwart7 I 1994 Growth hormone induces a DNA binding factor related to the interferon-stimulated $91-\mathrm{kDa}$ transcription factor. $J$ Biol Chem 269:4701-4704

7. Campbell GS, Meyer DJ, Raz R, Levy DE, Schwartzt J, Carter-Su C 1995 Activation of acute phase response factor (APRF)/stat3 transcription factor by growth hormone. J Biol Chem 270:3974-3979

8. Wood TJJ, Sliva D, Lobie PE, Pircher T, Gouilleux F, Wakao H, Gustafsson JA, Groner B, Norstedt G, Haldosen LA 1995 Mediation of growth hormone-dependent transcriptional activation by mammary gland factor/ Stat5. J Biol Chem 270:9448-9453

9. Darnell Jr JE, Kerr IM, Stark GR 1994 Jak-STAT pathways and transcriptional activation in response to IFNs and other extracellular signaling proteins. Science $264: 1415-1421$

10. Wen Z, Zhong Z, Darnell JE 1995 Maximal activation of transcription by Stat 1 and Stat3 requires both tyrosine and serine phosphorylation. Cell 82:241-250

11. Zhang $X$, Blenis J, Li H-C, Schindler $C$, Chen-Kiang $S$ 1995 Requirement of serine phosphorylation for formation of STAT-promoter complexes. Science 267: 1990-1994

12. Roupas $P$, Herington $A C 1994$ Postreceptor signaling mechanisms for growth hormone. Trends Endocrinol Metab 5:154-158

13. Le Cam A, Pantescu V, Paquereau L, Legraverend C Fauconnier G, Asins G 1994 Cis-acting elements controlling transcription from rat serine protease inhibitor 2.1 gene promoter. J Biol Chem 269:21532-21539

14. Ashcom G, Gurland G, Schwartz J 1992 Growth hormone synergizes with serum growth actors in inducing c-fos transcription in 3T3-F442A cells. Endocrinology 131:1915-1921

15. Sotiropoulos A, Moutoussamy S, Binart N, Kelly PA, Finidori J 1995 The membrane proximal region of the cytoplasmic domain of the growth hormone receptor is involved in the activation of Stat3. FEBS Lett 369:169-172

16. Sotiropoulos A, Perrot-Applanat M, Dinerstein H, Pallier A, Postel-Vinay MC, Finidori J, Kelly PA 1994 Distinct cytoplasmic regions of the growth hormone receptor are required for activation of Jak2, mitogen-activated protein kinase, and transcription. Endocrinology 135:1292-1298

17. Wakao $H$, Gouilleux F, Groner B 1994 Mammary gland factor (MGF) is a novel member of the cytokine regulated 
transcription factor gene family and confers the prolactin response. EMBO J 13:2182-2191

18. Thomis DC, Gurniak CB, Tivol E, Sharpe AH, Berg LJ 1995 Defects in $B$ lymphocyte maturation and T lymphocyte activation in mice lacking JAK3. Science 270:794-797

19. Russel SM, Tayebi N, Nakajima H, Riedy MC, Roberts JL Aman, MJ, Migone T-S, Nogushi M, Marker ML, Buckley $\mathrm{RH}$, O'Shea JJ, Leonard WJ 1995 Mutation of JAK3 in a patient with SCID: essential role of JAK3 in lymphoid development. Science 270:797-800

20. Nosaka T, van Deursen JMA, Witthuhn BA, McMickle AP, Doherty PC, Grosveld GC, Ihle JN 1995 Defective lymphoid development in mice lacking Jak3. Science 270:800-802

21. Zhuang H, Niu Z, HET-C, Patel SV, Wojchowski DM 1995 Erythropoietin-dependent inhibition of apoptosis is supported by carboxyl-truncated receptor forms and blocked by dominant-negative forms of Jak2. J Biol Chem 270:14500-14504

22. Wang YD, Wood WI 1995 Amino acids of the human growth hormone receptor that are required for proliferation and Jak-STAT signaling. Mol Endocrinol 9:303-311

23. Nicholson SE, Novak U, Ziegler SF, Layton JE 1995 Distinct regions of the granulocyte colony-stimulating factor receptor are required for tyrosine phosphorylation of the signaling molecules JAK2, Stat3, and p42, p44 MAPK. Blood 86:3698-3704

24. Gouilleux F, Wakao H, Mundt M, Groner B 1994 Prolactin induces phosphorylation of Tyr694 of Stat5(MGF), a prerequisite for DNA binding and induction of transcription. EMBO J 13:4361-4369

25. Mui AL-F, Wakao H, O'Farrell A-M, Harada N, Miyajima A 1995 Interleukin-3, granulocyte-macrophage colony stimulating factor and interleukin-5 transduce signals through two STAT5 homologs. EMBO J 14:1166-1175

26. Fujii $H$, Nakagawa $Y$, Schindler $U$, Kawahara A, Mori $H$, Gouilleux F, Groner B, Ihle JN, Minami Y, Miyazaki T, Taniguschi T 1995 Activation of Stat 5 by interleukin 2 requires a carboxy-terminal region of the interleukin 2 receptor $\beta$ chain but is not essential for the proliferative signal transmission. Proc Natl Acad Sci USA 92:5482-5486

27. VanderKuur JA, Wang $X$, Zhang L, Campbell GS, Allevato G, Billestrup N, Norstedt G, Carter-Su C 1994 Domains of the growth hormone receptor required for association and activation of JAK2 tyrosine kinase. J Biol Chem 269:21709-21717

28. Dinerstein $H$, Lago F, Goujon L, Ferrag F, Esposito N, Finidori J, Kelly PA, Postel-Vinay MC 1995 The prolinerich region of the growth hormone receptor is essential for Jak2 phosphorylation, activation of cell proliferation and gene transcription. Mol Endocrinol 9:1701-1707

29. Goujon L, Allevato G, Simonin G, Paquereau L, Le Cam A, Clark J, Nielsen JH, Dilane J, Postel-Vinay MC, Edery M, Kelly PA 1994 Cytoplasmic sequences of the growth hormone receptor necessary for signal transduction. Proc Natl Acad Sci USA 91:957-961

30. Moldrup A, Allevato G, Dyrberg T, Nielsen JH, Billestrup N 1991 Growth hormone action in rat insulinoma cells expressing truncated growth hormone receptors. J Biol
Chem 266:17441-17445

31. Yi T, Mui AL-F, Krystal G, Ihle JN 1993 Hematopoietic cell phosphatase associates with the interleukin-3 (IL-3) receptor $\beta$ chain and down-regulates IL-3-induced tyrosine phosphorylation and mitogenesis. Mol Cell Biol 13:7577-7586

32. Klingmuller U, Lorenz U, Cantley LC, Neel BG, Lodish HF 1995 Specific recruitment of SH-PTP1 to the erythropoietin receptor causes inactivation of Jak2 and termination proliferative signals. Cell 80:729-738

33. David M, Chen HE, Goelz S, Larner AC, Neel BG 1995 Differential regulation of the alpha/beta interferon-stimulated Jak/Stat pathway by the $\mathrm{SH} 2$ domain-containing tyrosine phosphatase SHPTP1. Mol Cell Biol 15:7050-7058

34. Ali S, Chen Z, Lebrun JJ, Vogel W, Kharitonenkov A, Kelly PA, Ullrich A 1996 PTP1D is a positive regulator of the prolactin signal leading to $\beta$-casein promoter activation. EMBO J 15:135-142

35. Stahl N, Farruggella TJ, Boulton TG, Zhong Z, Darnell Jr JE, Yancopoulos GD 1995 Choice of STATs and other substrates specified by modular tyrosine-based motifs in cytokine receptors. Science 267:1349

36. Wang YD, Wong K, Wood WI 1995 Intracellular tyrosine residues of the human growth hormone receptor are not required for the signaling of proliferation or Jak-STAT activation. J Biol Chem 270:7021-7024

37. Hackett RH, Wang YD, Larner AC 1995 Mapping of the cytoplasmic domain of the human growth hormone receptor required for the activation of JAK2 and Stat proteins. J Biol Chem 270:21326-21330

38. Gupta S, Yan H, Wong LH, Ralph S, Krolewski J, Schindler C 1996 The SH2 domains of Stat1 and Stat2 mediate multiple interactions in the transduction of IFN- $\alpha$ signals. EMBO J 15:1075-1084

39. Thomas MJ, Gronowski AM, Berry SA, Bergad PL, Rotwein $P 1995$ growth hormone rapidly activates rat serine protease inhibitor 2.1 gene transcription and induces a DNA-binding activity distinct from those of stat1,-3, and-4. Mol Cell Biol 15:12-18

40. Gouilleux F, Pallard C, Dusanter-Fourt I, Wakao H, Haldosen L-A, Norstedt G, Levy D, Groner B 1995 Prolactin, growth hormone, erythropoietin and granulocytemacrophage colony stimulating factor inducc MGF Stat5 DNA binding activity. EMBO $\mathrm{J}$ 14:2005-2013

41. Wang X, Souza SC, Kelder B, Gioffi JA, Kopchick JJ 1995 A 40-amino acid segment of the growth hormone receptor cytoplasmic domain is essential for $\mathrm{GH}$-induced tyrosine-phosphorylated cytosolic proteins. J Biol Chem 270:6261-6266

42. Astruc ME, Chabret C, Bali P, Gagne D, Pons M 1995 Prolonged treatment of breast cancer cells with antiestrogens increases the activating protein-1-mediated response: involvement of the estrogen receptor. Endocrinology 136:824-832

43. Sotiropoulos A, Goujon L, Simonin G, Kelly PA, PostelVinay MC, Finidori J 1993 Evidence for generation of the growth hormone-binding protein through proteolysis of the growth hormone membrane receptor. Endocrinology 132:1863-1865 